This is an unedited manuscript published in the Career Development International.

Please note that the published version underwent minor additional editing in style and content.

Complete reference:

Zhang, C., \& Hirschi, A. (2021). Forget about the money? A latent profile analysis of calling and work motivation in Chinese employees. Career Development International.

\title{
Forget About the Money? A Latent Profile Analysis of Calling and Work Motivation in
}

\section{Chinese Employees}

Chunyu Zhang ${ }^{1}$, Andreas Hirschi ${ }^{2}$

1 School of Psychology, Shaanxi Normal University, Xi'an, China

2 Institute of Psychology, University of Bern, Switzerland

\section{Author Note}

Acknowledgement: This research was supported by National Natural Science Foundation of China (71702092); the Humanity and Social Science Foundation of Ministry of Education of China (17XJC190008); and Shaanxi Province Postdoctoral Science Foundation (2017BSHYDZZ55).

Address all correspondence about this manuscript to Chunyu Zhang, School of Psychology, Shaanxi Normal University, Xi’an, China, chunyu.zhang@snnu.edu.cn 


\begin{abstract}
Purpose - Calling is typically associated with more intrinsic than extrinsic work motivation. This could give the impression that employees with a calling do not need or care about external rewards. To deepen the understanding of the relationship between calling and work motivation, we tested how calling is combined with different types of work motivation and how such combinations affect work outcomes differentially.

Design/methodology/approach - We applied latent profile analysis among Chinese employees with diverse occupations $(N=1,290)$ to identify calling and work motivation profiles and test their relations with work outcomes, assessed four months later.
\end{abstract}

Findings - Four profiles emerged: externally motivated low calling, moderately externally motivated calling, moderately motivated calling, and highly motivated calling. Employees with weaker and stronger callings indicated being extrinsically motivated for work. Employees in the highly motivated calling profile exhibited highest job satisfaction, lowest cynicism, and lowest turnover intentions, followed by employees in the moderately motivated calling profile, the moderately externally motivated calling profile, and the externally motivated low calling profile.

Implications - Our findings imply that employees with a strong calling do care about external rewards and also benefit from external incentives to work.

Originality/value - This study is the first to explore the differential relationship between calling and work motivation. Moreover, our findings offer insights regarding the underresearched notion that different types of calling predict work outcomes differently.

Keywords: Calling profiles, work motivation, external motivation, latent profile analysis, job satisfaction

Article classification: Research paper 
Over the past decades, the notion of calling has drawn significant scholarly attention (Duffy et al., 2018). Calling refers to a career orientation that ties one's personal meaning of work with helping others or contributing to society, and which stems from a transcendent or guiding force (for a review, see Duffy and Dik, 2013). Scholars tend to regard calling as distinguished from orientations focusing on the job (i.e., gaining an income) or career (i.e., personal advancement) (Willner et al., 2020; Wrzesniewski et al., 1997), thereby assuming that a calling relates more closely to intrinsic work motivation than extrinsic work motivation (Dobrow and Tosti-Kharas, 2011; Wrzesniewski et al., 1997). This is in line with research findings that people with a calling are willing to forego extrinsic rewards and willing to sacrifice money, time, and physical comfort at work (Bunderson and Thompson, 2009). Callings and work motivation are thus closely linked, and it is important to understand how calling and work motivation, particularly extrinsic motivation, are linked to better understand the nature and potential consequences of callings.

Prior research has delved into this issue. For example, Conway et al. (2015) found that calling is positively related to intrinsic and identified work motivation, but not to introjected work motivation. However, in Dobrow and Tosti-Kharas's (2011) study, they found that calling positively related to both intrinsic motivation and extrinsic motivation. Although these studies have offered important insights on the relationship between calling and work motivation, there are limitations to our knowledge. First, research with a variable-centered approach (e.g., regressions) provided contradictory results on how callings relate to different work motivations. This suggests that the relationship between calling and work motivation may not be straight forward and that research should consider using person-centered approaches to explore different types of calling in regard to their link with work motivation. This assumption is in line with more recent research suggesting that different forms of calling need to be differentiated and that studies suggesting only one type of calling (e.g., purely intrinsically motivated) might oversimplify the complex nature of callings (Dik and Shimizu, 2019; Shimizu et al., 2019; Thompson and Bunderson, 2019). However, this research is still emerging and not much is known about what types of calling exist. Accordingly, we adopted a person-centered approach with latent profile analysis (LPA), to identify individuals with profiles of calling and work motivation combinations. By doing so, we sought to provide new 
insights into the potentially complex relationship between calling and work motivation. Second, existing research established that calling is related to work motivations and different career or life outcomes (Duffy et al., 2018), but did not investigate if different combinations of calling and work motivation predict outcomes differently. By identifying profiles of calling and work motivation, we draw on the self-determination theory (SDT; Gagné and Deci, 2005) and explore how such profiles relate to work outcomes differentially (i.e., job satisfaction, cynicism, turnover intentions). These outcomes were selected because they are important work outcomes that relate to calling (e.g., Dobrow \& Tosti-Kharas, 2011) and work motivations (e.g., Graves et al., 2015; Howard et al., 2016). By doing so, we provide a more nuanced understanding of the work consequences of callings and work motivations.

To investigate these issues, we conducted a survey among a sample of Chinese employees with diverse occupations. Research confirmed that the notion of calling also applies in a Chinese context and that callings show similar, if not completely identical, characteristics with callings examined in Western contexts (Zhang et al., 2015a, b). However, compared to the Western context, the Chinese context may have distinct implications for work motivation. For example, research findings indicate that Chinese employees showed lower autonomous motivation than Canadian employees (Wang and Gagné, 2013). Moreover, in modern China, extrinsic work motivation may be very salient for many employees because of the influence of the ongoing economic and educational reforms (Zheng, 2005). Chinese employees have to adjust to market-driven competition, and thus more strongly lay emphasis on financial and materialistic rewards (Sun and Wang, 2010). Indeed, Inglehart (2003) found that Chinese individuals reported the highest levels of materialistic values compared to individuals from other countries. Thus, the combination of calling and work motivation in a Chinese context may be different from the Western context. To expand the knowledge on the nature and consequences of callings across cultures (Duffy and Dik, 2013), it is thus theoretically and practically meaningful to explore this topic in the Chinese context.

\section{Calling and Work Motivation}

Definitions of calling emphasize two different orientations (Dik and Shimizu, 2019): (1) a modern calling, conceptualized as being internally driven to work, emphasizing personal meaning, fulfillment, and passion for work (Dobrow and Tosti-Kharas, 2011); (2) a 
neoclassical calling, conceptualized as a career orientation that ties one's personal meaning of work with a tendency of helping others or contributing to society, and which stems from a transcendent or guiding force such as salient social needs or family legacy (Duffy and Dik, 2013). In the Chinese context, research shows that a calling integrates both the modern (e.g., passion, interest, self-actualization) and neoclassical (e.g., duty, salient social needs, destiny) elements (Zhang et al., 2015a).

According to SDT (Gagné and Deci, 2005), work motivation can be categorized into four different types following an autonomy continuum. Intrinsic motivation is the most autonomous motivation, resulting from the interest and enjoyment entailed in the work itself. Identified motivation is the second most autonomous motivation and refers to a motivation where individuals identify with the value of their work. A more controlled and less autonomous type of motivation is introjected motivation, representing working for reasons that have been accepted by the person as important but that have not been accepted as their own motivation, such as contingent self-esteem (to feel worthy), ego-involvements (to buttress the ego), and avoiding feeling guilty. Finally, external motivation is the least autonomous and most controlled form of motivation, referring to a work intention that is controlled by others, such as the intention of obtaining rewards or avoiding threats. Moreover, based on SDT (Gagné and Deci, 2005), external, introjected, and identified motivation types represent extrinsic motivation, compared to intrinsic motivation. Conceptually, calling is different from intrinsic, introjected, and external motivations because meaning, transcendent force, or prosocial intention are not the core components of those three motivations (Duffy and Dik, 2013). However, calling may closely relate to intrinsic motivation because both constructs stress the internal reasons of why people engage in their work (i.e., the passion aspect of calling and the enjoyment aspect of intrinsic motivation; Dobrow and Tosti-Kharas, 2011). Moreover, calling is closely related to, but different from, identified motivation because both share a focus on personally endorsed values to work (Conway et al., 2015).

Researchers have long recognized the association between calling and work motivation. A study with zookeepers found that those with a high calling showed a tendency to care less about extrinsic rewards, and were more willing to sacrifice money, time, and physical comfort for work (Bunderson and Thompson, 2009). In a long-term quantitative 
study, Dobrow and Heller (2015) showed that a strong calling predicted people prioritizing intrinsic over extrinsic benefits while making decisions to pursue a career as a professional musician. However, when directly examining the relationship between calling and work motivation, prior findings were inconsistent. Notably, in a study of the Church of England's clergy, Conway et al. (2015) found that calling positively related to intrinsic and identified motivation, but not to introjected motivation. However, with multiple occupation samples, Dobrow and Tosti-Kharas (2011) found that calling positively related to intrinsic motivation in their musician, artist, and manager samples but not in the business sample, whereas calling positively related to extrinsic motivation in their business and manager samples but not in the musician and artist samples.

\section{Profiles with Different Combinations of Calling and Work Motivation}

A person-centered approach focuses on how constructs combine within individuals (Spurk et al., 2020), extracting distinct profiles or classes of individuals from the constructs. A few studies have adapted such an approach to investigate callings. For example, Hirschi (2011) identified three profiles of calling in German university students in which a notable profile was characterized as a subgroup of individuals with a calling endorsing a variety of different work values, including placing high values on pay, autonomy, and security. This suggests that callings could differently combine with different forms of work motivation to generate different profiles.

As to work motivation, research has also explored profiles based on its different types. For example, based on four motivation types from SDT (i.e., external, introjected, identified, intrinsic), Graves et al. (2015) identified six motivation profiles in a sample of managers: a self-determined profile, indicated by high identified and intrinsic motivation, moderately low introjected motivation, and low external motivation; a high internal profile, indicated by average external motivation and high introjected, identified, and intrinsic motivation; a moderately high profile, referring to a group of people showing high levels of all four motivations; and three others, that is, very low internal, low internal, and moderately low internal profiles. Similarly, Howard et al. (2016) also examined the four types of motivation plus amotivation (i.e., the absence of any desire or reason to execute work) from SDT and identified four motivation profiles in Canadian and Belgian employees: a balanced motivation 
profile, an amotivated profile, an autonomously regulated profile, and a highly motivated profile. Moreover, in a study with Chinese employees, Moran et al. (2012) found five profiles: two profiles of motivated and moderate, a self-determined profile, a low autonomy profile, and a low introjection profile. These studies show that different types of motivation can cooccur to represent distinct motivational profiles.

In our study, we focus on the combinations of calling with different types of work motivation. Several profiles are plausible. For example, because of the presumed positive association of calling with intrinsic and identified motivation and low association with introjected or external motivation (Conway et al., 2015; Dobrow and Tosti-Kharas, 2011), employees with a strong calling may have more autonomous motivation and less controlled motivation, presenting a profile of autonomously motivated calling. At the other extreme, given that employees in China often place a strong emphasis on external benefits (Inglehart, 2003; Sun and Wang, 2010), employees without a calling or very low levels of calling may endorse more external motivation and less other motivation types, presenting a profile of externally motivated low calling. Moreover, because of the positive association of calling with both intrinsic and extrinsic motivation (Dobrow and Tosti-Kharas, 2011), we expect that some employees with a calling may have high levels of all four motivation types, reflecting a profile of highly motivated calling. Alternatively, because calling is driven by some external forces (e.g., family legacy, needs of society; Duffy and Dik, 2013; Zhang et al., 2015a), some employees with a strong calling may endorse high levels of introjected motivation and low levels of other motivation types, reflecting a profile of introjected motivated calling. These profiles might be possibly extracted in our analysis. Thus, we propose:

Hypothesis 1: Four calling profiles exist: (1) autonomously motivated, (2) externally motivated low calling, (3) highly motivated, and (4) introjected motivated.

\section{Outcomes of Different Profiles}

In addition to identifying profiles with different combinations of calling and work motivation, we sought to explore how profile membership is related to important work outcomes in terms of job satisfaction, cynicism (a specific dimension of job burnout, referring to a negative, callous, or excessively detached response to various aspects of the job; Maslach et al., 2001), and turnover intentions (the propensity of employees to leave their organization). 
Prior research has found that calling is related to greater job satisfaction (Duffy et al., 2018; Wrzesniewski et al., 1997), less burnout (Creed et al., 2014), and less turnover intentions (Esteves and Lopes, 2017). However, it is not clear how profiles with different combinations of calling and work motivation relate to such outcomes. According to SDT (Gagné and Deci, 2005), more autonomous motivation predicts higher well-being and performance, such as greater job satisfaction, as well as less job burnout and lower turnover intentions (Deci et al., 2017). Thus, employees with a more autonomously motivated calling may show more positive work experiences than employees with a more controlled motivated calling. Accordingly, we expect that employees with externally motivated low calling may exhibit the lowest job satisfaction, highest cynicism, and highest turnover intentions compared to employees with other profiles. Employees with an autonomously motivated calling may exhibit higher job satisfaction, lower cynicism, and lower turnover intentions than those with introjected motivated calling or externally motivated low calling. Moreover, the most positive configuration may be that employees perceive a strong calling and simultaneously endorse high levels of all four motivation types. Such a high convergence of autonomous and controlled motivations has been found to relate to particularly high levels of job satisfaction and low job burnout (Graves et al., 2015; Howard et al., 2016). Taken together, we propose:

Hypothesis 2: Employees with highly motivated calling exhibit the highest job satisfaction, lowest cynicism, and lowest turnover intentions, followed by employees with autonomously motivated calling, introjected motivated calling, and externally motivated low calling.

\section{Method}

\section{Participants and Procedure}

We recruited participants from an online data collection service in China (www.wjx.cn), which is a professional and reliable website for collecting academic and commercial research data in China. Similar to the procedure of Amazon Mechanical Turk (MTurk), an online survey link was built and disseminated to participants who had registered in wjx.cn and work full time in mainland China. The survey of Time 1 (T1) was conducted at the end of July 2018, and included measures of calling and work motivation. Four months later, we administered the second survey (T2) and included measures of job satisfaction, 
cynicism, and turnover intentions. To improve the response rate, we offered 10 China Yuan (CNY) at each wave as an incentive to each participant who provided valid responses.

A total of approximately 2,600 participants were invited to the survey at $\mathrm{T} 1$ and 1,678 $(64.5 \%)$ responded to the survey. We implemented several strategies to enhance data quality. We excluded participants who completed the survey in a very short time (i.e., less than 5 seconds to respond to an item). We additionally included quality control items in the survey (e.g., "I distort this survey by responding to the items randomly"). Participants who answered "agree" or "strongly agree" were removed. After removing 388 (23.1\%) participants using the above criterion, we identified 1,290 (49.6\%) participants who provided valid responses at T1. At T2, 47\% $(N=605)$ again provided valid responses. The sample consisted of 59\% women, with a mean age of 29.70 years ( $S D=7.40$, ranging from 18 to 64 years) at T1. As regards educational background, $4 \%$ reported not having completed high school, $13 \%$ had completed vocational school, $71 \%$ had completed college, and $12 \%$ had completed graduate school. The mean monthly income was CNY 7,734.19 (approx. USD 1,100), $S D=\mathrm{CNY} 5,751.88$ (approx. USD 810). Participants reported a wide range of occupations, including manager, teacher, accountant, salesman, designer, IT engineer, and office administrator.

We tested the potential impact of "missingness" by creating a dummy variable that separated the participants who participated in both waves from those who participated only at T1 (Little, 2013). We found that missingness was nonsignificantly related to any of the study variables at $\mathrm{T} 1$ or demographic variables of gender, educational background, and income. Participants who only participated at T1 were younger ( $M=28.03$ vs $31.58, t=8.82, p<.001$, Cohen's $d=.49$ ). However, including age as a control variable in the subsequent analyses did not change the results. Thus, attrition may not significantly affect the results of this study.

\section{Measures}

Table 1 shows the reliability coefficients, means, and standard deviations, and bivariate correlations for all measures.

Calling. The 11-item Chinese Calling Scale (Zhang et al., 2015b) was used, which assesses the presence of calling using three dimensions: guiding force, meaning and purpose, and altruism. An example item is, "I feel that a kind of intangible power impels me to pursue my career." (guiding force). The items were answered on a five-point scale that ranged from 1 
(strongly disagree) to 5 (strongly agree). Zhang et al. (2015b) reported that the alphas of the scale ranged from .77 to .84 in different samples. As done in previous studies (e.g., Zhang et al., 2015b), we averaged the items to create a total calling score ${ }^{1}$.

Work motivation. The Chinese language version of Motivation at Work Scale (Gagné et al., 2010; Zhang et al., 2016) was used to assess work motivations. Each type of motivation was measured by three items. Participants were asked to think about the reason why they do their job. Example items are "Because I have fun doing my job" (intrinsic); "Because it allows me to reach my life goals" (identified); "Because my work is my life and I don't want to fail" (introjected); and "Because this job affords me a certain standard of living" (external). The response scale ranged from 1 (not at all) to 7 (exactly). Gagné et al. (2010) reported good Cronbach's alpha for the four subscales (ranging from .75 to .93). Zhang et al. (2016) also supported the same (ranging from .73 to .94) among Chinese employees.

Job satisfaction. We used the five-item overall job satisfaction scale from Judge et al. (1998). We translated the items into Chinese using back-translation procedures. Participants responded on a seven-point scale ranging from 1 (strongly disagree) to 7 (strongly agree). An example item is, "I feel fairly satisfied with my present job." Judge et al. (1998) reported Cronbach's alpha of .84-.92.

Cynicism. We used the Chinese language version of cynicism subscale from Maslach Burnout Inventory-General Survey (Li and Shi, 2003; Schaufeli et al., 1996), which consists of four items (e.g., "I have become less enthusiastic about my work."). The seven-point response scale ranged from 1 (never) to 7 (daily). Schaufeli et al. (1996) reported a good internal consistency $(\alpha=.73-.84)$. Among Chinese employees, this scale also showed good reliability $(\alpha=.83-.85$; Li and Shi, 2003).

Turnover intentions. We used three items in Chinese derived from Hui et al. (2007) to assess participants' intentions to leave their job (e.g., "I often think of leaving the organization.”). The response scale ranged from 1 (strongly disagree) to 5 (strongly agree).

\footnotetext{
${ }^{1}$ We conducted a series of confirmatory factor analyses to test the construct validity of calling and work motivations, and test if the constructs of calling, work motivations, and the outcome variables were distinct. The results supported the construct validity of calling and work motivation and the empirical distinction of all variables (results are reported in the supplemental material to this paper).
} 
Hui et al. (2007) reported an acceptable reliability of this scale in a Chinese employee sample $(\alpha=.60)$

Consideration of control variables. To test the robustness of our findings, we considered gender, age, educational background, and income as potential controls in our analyses. However, the results did not change when including these controls and we thus report the results without control variables to increase power and interpretability of results.

\section{Analytical Approach}

We used LPA analysis in Mplus (version 7; Muthén and Muthén, 1998-2012) to explore profiles with different combinations of calling and work motivation. LPA aims to find meaningful subgroups/profiles of people that exhibit similar patterns in measured continuous variables (Tein et al., 2013). To decide on the number of profiles, several fit statistics were adopted. First, lower Akaike's Information Criterion (AIC), Bayesian Information Criterion (BIC), and sample-size adjusted BIC (SABIC) were used to indicate a better profile solution (Tein et al., 2013). Second, two likelihood ratio statistic tests were adopted, including LoMendell-Rubin adjusted likelihood ratio test (LRT) and bootstrap likelihood ratio test (BLRT) (Tein et al., 2013). A significant probability value (e.g., $p<.05)$ indicates that the $\mathrm{K}$ profiles solution provides a better fit to the observed data than the $\mathrm{K}-1$ profiles solution. Third, entropy was adopted to evaluate the classification accuracy. A higher value of entropy indicates a better profile solution (Tein et al., 2013). Finally, we also considered whether the suggested profile solution is theoretically meaningful.

After obtaining the most appropriate number of profiles, we tested how these profiles relate to work outcomes by including auxiliary variables with the DU3STEP command in MPlus (Asparouhov and Muthén, 2014). To address missingness when examining the relationship between LPA profiles and outcomes at T2, we adapted a full information maximum likelihood to estimate missing data (Little, 2013).

\section{Results}

\section{Determining Profiles with Different Combinations of Calling and Work motivation}

We specified LPA models ranging from 2 to 7 profiles. Table 2 presents their fit indices and likelihood ratio statistics. For the 2-profile models, AIC, BIC, and SABIC values were the highest while entropy value was the lowest across all the models. Thus, the 2-profile 
model was rejected. In other models, AIC, BIC, and SABIC values dramatically declined until the 4-profile model. The 4-profle model exhibited the highest entropy value among all the models. The 5-profile model exhibited the second highest entropy. Moreover, the nonsignificant LRT indicated that the 5-profile model did not fit significantly better than the 4-profile model. Similarly, the 6- and 7-profile models also did not show a better fit than the 5- and 6-profile models, respectively. Taken together, the 4-profile model was considered the best solution because it yielded theoretically meaningful classifications with low AIC, BIC, and SABIC values and high entropy values.

As shown in Table 3 and Figure 1, the first class included 38 (3\%) participants, characterizing an externally motivated low calling profile, in which the levels of calling, intrinsic motivation, identified motivation, and introjected motivation were all low, whereas external motivation was high. The second profile included $228(18 \%)$ participants, characterizing a moderately externally motivated calling profile. Participants in this profile had moderate calling levels, lower than moderate levels of intrinsic motivation, identified motivation, and introjected motivation, and high levels of external motivation. The third profile included 593 (46\%) participants, characterizing a moderately motivated calling profile. Participants in this profile exhibited moderate levels of calling, intrinsic motivation, identified motivation and introjected motivation, and high levels of external motivation. The fourth profile included 431 (33\%) participants, characterizing a highly motivated calling profile, in which the levels of calling and all types of work motivation were the highest compared to the other profiles. Taken together, these results partially supported Hypothesis 1 but did not confirm profiles of autonomously motivated calling and introjected motivated calling.

\section{Testing Outcomes of Different Profiles}

We then applied the DU3STEP command in Mplus by including auxiliary variables for testing the relationship between different profiles and work outcomes (i.e., job satisfaction, cynicism, and turnover intentions). We found significant differences among the four profiles on all three outcomes. As shown in Table 4, employees with highly motivated calling exhibited the highest job satisfaction, lowest cynicism, and lowest turnover intentions compared with employees in other profiles. At the other extreme, employees with externally motivated low calling exhibited the lowest job satisfaction, highest cynicism, and highest 
turnover intentions compared with employees in other profiles. Employees with moderately motivated calling exhibited higher job satisfaction and lower cynicism than employees in the moderately externally motivated calling profile. However, levels of turnover intentions in the moderately motivated calling profile were not significantly different from those in the moderately externally motivated calling profile. These results partly supported Hypothesis 2, that different profiles of calling and work motivations relate differently to work outcomes.

\section{Discussion}

This study aimed to investigate the relationship between calling and work motivation using a person-centered approach. Specifically, we used LPA analysis in Chinese employees to explore the different ways calling and different types of work motivation, ranging from intrinsically to externally motivated, can co-occur and how such profiles differentially relate to work outcomes in terms of job satisfaction, cynicism, and turnover intentions. The findings add notable insights to the literature on calling in several important ways.

Our findings suggest that profiles with different combinations of calling and work motivation exist. This is in line with prior notions and findings that support that different types of calling exist (e.g., Dik and Shimizu, 2019; Hirschi, 2011; Thompson and Bunderson, 2019). By integrating calling with work motivation, we found four profiles: (1) an externally motivated low calling profile, in which only external motivation was high and the levels of calling and other types of motivation were low; (2) a moderately externally motivated calling profile, in which external motivation was still high and the levels of calling and other motivations were lower than moderate; (3) a moderately motivated calling profile, characterized by a high level of external motivation and moderate levels of calling and other motivations; and (4) a highly motivated calling profile, in which the levels of calling and all types of work motivation were the highest compared to other profiles. These findings extend prior research on the relationship between calling and work motivation (e.g., Conway et al., 2015; Dobrow and Tosti-Kharas, 2011). Specifically, first, we found that external motivation was present in all four profiles. Second, we did not find a calling profile that was characterized by high levels of autonomous motivations (i.e., intrinsic and identified motivation) and low levels of controlled motivations (i.e., introjected and external motivation). This suggests that Chinese employees with a calling do not strongly prioritize 
intrinsic and identified motivation over external motivation. Combined, these findings provide an important insight into how individuals with a calling are externally motivated with regard to their work. That is, although prior research suggests that individuals with a calling prioritize intrinsic over extrinsic rewards in work and career pursuits (Dobrow and Heller, 2015), we found employees with a strong calling emphasizing external factors at work to a comparable degree as employees with a low calling. This challenges the notion that people with a calling are mostly driven by intrinsic work rewards and emphasize external work rewards less. This assertion might be particularly true in a Chinese context in which individuals show a significantly higher level of external motivation or values compared to individuals in other cultural contexts (Inglehart, 2003).

However, our results also showed that employees who emphasized external rewards without any comparable emphasis on intrinsic enjoyment or identified motivation were more likely to exhibit a weak level of calling. This suggests that although extrinsic motivation is not in contradiction to having a calling, individuals with a strong sense of calling are unlikely to be only extrinsically motivated for work, without simultaneously also showing high intrinsic and identified motivation. Similarly, we did not find a calling profile that combined high levels of introjected motivation and low levels of other motivations. These results confirm the notion that intrinsic and identified work motivations are key ingredients to experiencing a calling (Conway et al., 2015; Thompson and Bunderson, 2019; Wrzesniewski et al., 1997). In sum, our findings offer a person-centered perspective to understanding the relationship between calling and work motivations. Future research could consider using alternative perspectives to study this relationship. For example, longitudinal research could examine how callings and work motivations are related over time.

Moreover, our findings suggest that profiles with different combinations of calling and work motivation relate to work outcomes differentially. This extends prior research on the role of calling and work motivation (Conway et al., 2015). Our results indicate that employees in the highly motivated calling profile exhibited higher job satisfaction, lower cynicism, and lower turnover intentions than those in other profiles. At the other extreme, employees with externally motivated low calling exhibited lower job satisfaction, higher cynicism, and higher turnover intentions than those in other profiles. On the one hand, these results are in line with 
prior findings that the absence of a calling and strong emphasis on external benefits related to negative work outcomes (Wrzesniewski et al., 1997). On the other hand, these results are generally consistent with SDT (Gagné and Deci, 2005) that more autonomous motivation relates to higher well-being and performance. Specifically, a low calling with an emphasis on external motivation may have a negative role on work outcomes when it is not accompanied by a comparable emphasis on intrinsic motivation. Moreover, our results indicate that external motivation does not have a negative effect if it is accompanied by high levels of calling and intrinsic motivation. However, our results do not address the underlying mechanism of these relationships (i.e., mediators and moderators). Future research should explore such mechanisms to more fully explain how calling and work motivations relate to work outcomes.

\section{Limitations and Future Research}

Several limitations should be considered when interpreting our findings. First, our findings were based on a sample of Chinese employees. While the extension of calling research to a non-Western context is a clear strength of our study, the generalizability of our findings to employees in other contexts should be made with caution. As prior research found, Chinese individuals typically show higher levels of external motivation or values (Inglehart, 2003). Thus, combinations of calling and work motivation might be different in other cultural contexts. Second, we used a time-lagged design with four months to assess calling and work motivation profiles in relation to work outcomes. Although this design is a strength to reduce common method bias, it does not allow drawing causal inferences and we could not test the potential mutual relationships between calling/work motivation and work outcomes. Studies that examine all variables repeatedly over time would be needed to assess such dynamics. Third, participants in our study were relatively young. Given that older workers may have different work motivations (Stamov-Roßnagel and Hertel, 2010), the generalizability of our findings to older employees should be made with caution and could be explored by future research. Fourth, we only focused on and measured four common types of motivation based on SDT. Other types of work motivation (i.e., amotivation, integrated motivation) were not included. Future studies should address additional work motivations to explore how they combine with calling. Finally, this study conceptualized and measured calling borrowing significantly from its neoclassical conceptualization and, therefore, the generalizability of our 
findings to purely modern conceptualization measures of calling (e.g., Dobrow and TostiKharas, 2011) should be made with caution. Future research could further explore the combinations of a modern calling and work motivation.

\section{Practical Implications}

Our results highlight the importance of recognizing the relationship between calling and work motivation for organizations and employees. First, organizations should realize that having a calling does not mean that employees necessarily care less about external benefits or rewards. Employing employees with a calling is thus not an excuse to support potential selfexploitation and withholding adequate external incentives or financial rewards. As our results suggest, this would not correspond to the motivational orientations of many employees with a calling and could result in negative outcomes in terms of dissatisfaction, burnout, and turnover. Second, our results suggest that if employees only focus on external rewards but ignore a calling and autonomous motivation, they might experience less job satisfaction as well as higher cynicism and turnover intentions. Thus, organizations should recognize that to achieve higher employee well-being and better retention at work, promoting a calling and autonomous motivation might be beneficial. That is, while adequate external rewards are necessary, fostering an inner passion, meaning, enjoyment, and duty in work is crucial. 


\section{References}

Asparouhov, T. and Muthén, B. (2014), “Auxiliary variables in mixture modeling: Three-step approaches using Mplus”, Structural Equation Modeling, Vol. 21 No. 3, pp. 329-341.

Bunderson, J. S. and Thompson, J. A. (2009), “The call of the wild: Zookeepers, callings, and the double-edged sword of deeply meaningful work", Administrative Science Quarterly, Vol. 54 No. 1, pp. 32-57.

Conway, N., Clinton, M., Sturges, J. and Budjanovcanin, A. (2015), "Using self-determination theory to understand the relationship between calling enactment and daily well-being", Journal of Organizational Behavior, Vol. 36 No. 8, pp. 1114-1131.

Creed, P. A., Rogers, M. E., Praskova, A. and Searle, J. (2014), "Career calling as a personal resource moderator between environmental demands and burnout in Australian junior doctors", Journal of Career Development, Vol. 41 No. 6, pp. 547-561.

Deci, E. L., Olafsen, A. H. and Ryan, R. M. (2017), "Self-determination theory in work organizations: The state of a science", Annual Review of Organizational Psychology and Organizational Behavior, Vol. 4 No. 1, pp. 19-43.

Dik, B. J. and Shimizu, A. B. (2019), "Multiple meanings of calling: Next steps for studying an evolving construct”, Journal of Career Assessment, Vol. 27 No. 2, pp. 323-336.

Dobrow, S. R. and Heller, D. (2015), "Follow your heart or your head? A longitudinal study of the facilitating role of calling and ability in the pursuit of a challenging career", Journal of Applied Psychology, Vol. 100 No.3, pp. 695-712.

Dobrow, S. R. and Tosti-Kharas, J. (2011), “Calling: The development of a scale measure”, Personnel Psychology, Vol. 64 No. 4, pp. 1001-1049.

Duffy, R. D. and Dik, B. J. (2013), "Research on calling: What have we learned and where are we going?" Journal of Vocational Behavior, Vol. 83, pp. 428-436.

Duffy, R. D., Dik, B. J., Douglass, R. P., England, J. W. and Velez, B. L. (2018), “Work as a calling: A theoretical model”, Journal of Counseling Psychology, Vol. 65 No. 4, pp. 423-439.

Esteves, T. and Lopes, M. P. (2017), “Crafting a calling: The mediating role of calling between challenging job demands and turnover intention", Journal of Career Development, Vol. 44 No. 1, pp. 34-48. 
Gagné, M. and Deci, E. L. (2005), "Self-determination theory and work motivation", Journal of Organizational Behavior, Vol. 26 No. 4, pp. 331-362.

Gagné, M., Forest, J., Gilbert, M. -H., Aubé, C., Morin, E. and Malorni, A. (2010), “The motivation at work scale: Validation evidence in two languages", Educational and Psychological Measurement, Vol. 70 No. 4, pp. 628-646.

Graves, L. M., Cullen, K. L., Lester, H. F., Ruderman, M. N. and Gentry, W. A. (2015), "Managerial motivational profiles: Composition, antecedents, and consequences", Journal of Vocational Behavior, Vol. 87, pp. 32-42.

Hirschi, A. (2011), "Callings in career: A typological approach to essential and optional components", Journal of Vocational Behavior, Vol. 79 No. 1, pp. 60-73.

Howard, J., Gagné, M., Morin, A. J. S. and Van den Broeck, A. (2016), “Motivation profiles at work: A self-determination theory approach", Journal of Vocational Behavior, Vol. 9596, pp. 74-89.

Hui, C., Wong, A. and Tjosvold, D. (2007), "Turnover intention and performance in China: The role of positive affectivity, Chinese values, perceived organizational support and constructive controversy", Journal of Occupational and Organizational Psychology, Vol. 80 No. 4, 735-751.

Inglehart, R. (2003), Human values and social change: findings from the Values Surveys. Brill.

Judge, T. A., Locke, E. A., Durham, C. C. and Kluger, A. N. (1998), "Dispositional effects on job and life satisfaction: The role of core evaluations", Journal of Applied Psychology, Vol. 83 No. 1, pp. 17-34.

Li, C. and Shi, K. (2003), “The influence of distributive justice and procedural justice on job burnout", Acta Psychologica Sinica, Vol. 35 No. 5, pp. 677-684.

Little, T. D. (2013), Longitudinal structural equation modeling. New York, NY: Guilford. Maslach, C., Schaufeli, W. B., and Leiter, M. P. (2001), “Job burnout”, Annual Review of Psychology, Vol. 52 No. 1, pp. 397-422.

Moran, M., Diefendorff, J., Kim, T. and Liu, Z. (2012), “A profile approach to selfdetermination theory motivations at work", Journal of Vocational Behavior, Vol. 81 No. 3, pp. 354-363. 
Muthén, B. O. and Muthén, L. K. (1998-2012), Mplus user's guide. Seventh edition. Los Angeles, CA: Muthén \& Muthén.

Schaufeli, W. B., Leiter, M. P., Maslach, C. and Jackson, S. E. (1996), “The MBI-General Survey”, In C. Maslach, S. E. Jackson, \& M. P. Leiter (Eds.), Maslach Burnout Inventory manual. Consulting Psychologists Press.

Shimizu, A. B., Dik, B. J. and Conner, B. T. (2019), “Conceptualizing calling: Cluster and taxometric analyses", Journal of Vocational Behavior, Vol. 114, pp. 7-18.

Spurk, D., Hirschi, A., Wang, W., Valero, D. and Kauffeld, S. (2020), "Latent profile analysis: A review and "how to" guide of its application within vocational behavior research", Journal of Vocational Behavior, Vol. 120, pp. 103445.

Stamov-Roßnagel, C., and Hertel, G. (2010), “Older workers' motivation: against the myth of general decline", Management Decision, Vol. 48 No. 6, pp. 894-906.

Sun, J. and Wang, X. (2010), "Value differences between generations in China: A study in Shanghai", Journal of Youth Studies, Vol. 13 No. 1, pp. 65-81.

Tein, J.-Y., Coxe, S. and Cham, H. (2013), "Statistical power to detect the correct number of classes in latent profile analysis", Structural Equation Modeling, Vol. 20 No. 4, pp. $640-657$.

Thompson, J. A. and Bunderson, J. S. (2019), "Research on work as a calling...and how to make it matter”, Annual Review of Organizational Psychology and Organizational Behavior, Vol. 6, pp. 421-443.

Wang, Z. and Gagné, M. (2012), “A Chinese-Canadian cross-cultural investigation of transformational leadership, autonomous motivation, and collectivistic value", Journal of Leadership \& Organizational Studies, Vol. 20 No. 1, pp. 134-142.

Willner, T., Lipshits-Braziler, Y. and Gati, I. (2020), "Construction and initial validation of the Work Orientation Questionnaire", Journal of Career Assessment, Vol. 28 No. 1, pp. 109-127.

Wrzesniewski, A., McCauley, C., Rozin, P. and Schwartz, B. (1997), “Jobs, careers, and callings: People's relations to their work", Journal of Research in Personality, Vol. 31 No. 1, pp. 21-33.

Zhang, C., Dik, B. J., Wei, J. and Zhang, J. (2015a), "Work as a calling in China: A qualitative 
study of Chinese college students", Journal of Career Assessment, Vol. 23 No. 2, pp. 236-249.

Zhang, C., Herrmann, A., Hirschi, A., Wei, J. and Zhang, J. (2015b), “Assessing calling in Chinese college students: Development of a measure and its relation to hope", Journal of Career Assessment, Vol. 23 No. 4, pp. 582-596.

Zhang, J., Song, Y. and Liu, X. (2016), “Undermining effect exists or not: Relationship between extrinsic and intrinsic motivation in workplace", Acta Psychologica Sinica, Vol. 48 No. 1, pp. 73-83.

Zheng, B. (2005), “China's "peaceful rise” to great-power status”, Foreign Affairs, Vol. 84 No. 5, pp. 18-24. 


\section{Table 1}

Correlations, Reliabilities, Means, and Standard Deviations of the Assessed Variables

\begin{tabular}{|c|c|c|c|c|c|c|c|c|c|c|}
\hline Variables & $M$ & $S D$ & 1 & 2 & 3 & 4 & 5 & 6 & 7 & 8 \\
\hline 1. Calling T1 & 3.63 & .53 & .80 & & & & & & & \\
\hline 2. Intrinsic motivation $\mathrm{T} 1$ & 4.52 & 1.23 & $.51 * *$ & .89 & & & & & & \\
\hline 3. Identified motivation $\mathrm{T} 1$ & 4.72 & 1.21 & $.49 * *$ & $.66^{* *}$ & .84 & & & & & \\
\hline 4. Introjected motivation $\mathrm{T} 1$ & 4.00 & 1.20 & $.36^{* *}$ & $.29 * *$ & $.44 * *$ & .75 & & & & \\
\hline 5. External motivation $\mathrm{T} 1$ & 5.41 & 1.05 & $.07 *$ & .05 & $.19 * *$ & $.25^{* *}$ & .80 & & & \\
\hline 6. Job satisfaction $\mathrm{T} 2$ & 4.37 & 1.00 & $.42 * *$ & $.54 * *$ & $.53 * *$ & $.30^{* *}$ & $.11^{* *}$ & .81 & & \\
\hline 7. Cynicism T2 & 3.39 & 1.33 & $-.35 * *$ & $-.41 * *$ & $-.44 * *$ & $-.19 * *$ & $-.09 *$ & $-.75 * *$ & .87 & \\
\hline 8. Turnover intentions $\mathrm{T} 2$ & 2.49 & .88 & $-.32 * *$ & $-.38 * *$ & $-.46 * *$ & $-.24 * *$ & $-.19 * *$ & $-.64 * *$ & $.63 * *$ & .74 \\
\hline
\end{tabular}

Note. Numbers in diagonal in italic are the Cronbach's alpha reliability coefficients. $N_{T 1}=1290, N_{T 2}=605 .{ }^{*} p<.05 .{ }^{* *} p<.01$. 


\section{Table 2}

Results of Latent Profile Analysis with Calling and Work Motivations as Profile Indicators

\begin{tabular}{lcccccccccc}
\hline No. of profiles & LL & FP & Scaling & AIC & BIC & SABIC & LRT $p$ & BLRT $p$ & Entropy \\
\hline 2 & -8630.55 & 16 & 1.35 & 17293.09 & 17375.69 & 17324.87 & .00 & .00 & .73 \\
3 & -8432.96 & 22 & 1.36 & 16909.92 & 17023.49 & 16953.60 & .03 & .00 & .76 \\
$\mathbf{4}$ & $\mathbf{- 8 3 5 8 . 9 0}$ & $\mathbf{2 8}$ & $\mathbf{1 . 2 6}$ & $\mathbf{1 6 7 7 3 . 8 0}$ & $\mathbf{1 6 9 1 8 . 3 4}$ & $\mathbf{1 6 8 2 9 . 4 0}$ & $\mathbf{. 0 1}$ & $\mathbf{. 0 0}$ & $\mathbf{. 7 8}$ \\
5 & -8327.48 & 34 & 1.36 & 16722.97 & 16898.49 & 16790.49 & .14 & .00 & .78 \\
6 & -8295.70 & 40 & 1.42 & 16671.39 & 16877.89 & 16750.83 & .16 & .00 & .73 \\
7 & -8267.81 & 46 & 1.36 & 16627.61 & 16865.08 & 16718.96 & .12 & .00 & .76
\end{tabular}

Note: $N=1290 . \mathrm{LL}=$ model log-likelihood; $\mathrm{FP}=$ number of free parameters. The selected 4-profile solution is in bold. 


\section{Table 3}

Characteristics for the Four Latent Profiles with Different Combinations of Calling and Work Motivations

\begin{tabular}{|c|c|c|c|c|c|c|c|c|c|c|c|}
\hline \multirow[b]{2}{*}{ Latent Profiles } & \multirow[b]{2}{*}{$N(\%)$} & \multicolumn{2}{|c|}{ Calling } & \multicolumn{2}{|c|}{ Intrinsic } & \multicolumn{2}{|c|}{ Identified } & \multicolumn{2}{|c|}{ Introjected } & \multicolumn{2}{|c|}{ External } \\
\hline & & $M$ & $S E$ & $M$ & $S E$ & $M$ & $S E$ & $M$ & $S E$ & $M$ & $S E$ \\
\hline 1. Externally motivated low calling & $38(3 \%)$ & 2.80 & .14 & 1.92 & .19 & 1.58 & .13 & 2.02 & .21 & 4.94 & .33 \\
\hline 2. Moderately externally motivated calling & $228(18 \%)$ & 3.28 & .05 & 3.30 & .12 & 3.27 & .11 & 3.42 & .09 & 5.10 & .10 \\
\hline 3. Moderately motivated calling & $593(46 \%)$ & 3.54 & .03 & 4.43 & .08 & 4.70 & .07 & 3.88 & .06 & 5.44 & .05 \\
\hline 4. Highly motivated calling & $431(33 \%)$ & 4.03 & .03 & 5.55 & .05 & 5.83 & .05 & 4.65 & .07 & 5.58 & .06 \\
\hline
\end{tabular}




\section{Table 4}

Results of Predicting Outcomes of Latent Profile Membership

\begin{tabular}{|c|c|c|c|c|c|c|}
\hline \multirow[b]{2}{*}{ Latent Profiles } & \multicolumn{2}{|c|}{ Job satisfaction $\mathrm{T} 2$} & \multicolumn{2}{|c|}{ Cynicism T2 } & \multicolumn{2}{|c|}{ Turnover intentions T2 } \\
\hline & $M$ & $S E$ & $M$ & $S E$ & $M$ & $S E$ \\
\hline 1. Externally motivated low calling & $2.442,3,4$ & .36 & $5.082,3,4$ & .35 & $3.462,3,4$ & .22 \\
\hline 2. Moderately externally motivated calling & $3.71_{1,3,4}$ & .10 & $4.14_{1,3,4}$ & .14 & $3.161,4$ & .11 \\
\hline 3. Moderately motivated calling & $4.261 .2,4$ & .06 & $3.67_{1,2,4}$ & .09 & $2.51_{1,4}$ & .08 \\
\hline 4. Highly motivated calling & $5.06_{1,2,3}$ & .06 & $2.41_{1,2,3}$ & .10 & $1.99_{1,2,3}$ & .09 \\
\hline$\chi^{2}$ & \multicolumn{2}{|c|}{$238.51 * * *$} & \multicolumn{2}{|c|}{$169.87 * * *$} & \multicolumn{2}{|c|}{$115.73 * * *$} \\
\hline
\end{tabular}

Note: All analyses were run using the 3-step ML (DU3STEP) procedure in Mplus. Subscripts indicate profiles that are significantly different at $p$

$<.05$. The chi-square indicates the significance of the overall difference test. $* * * p<.001$. 


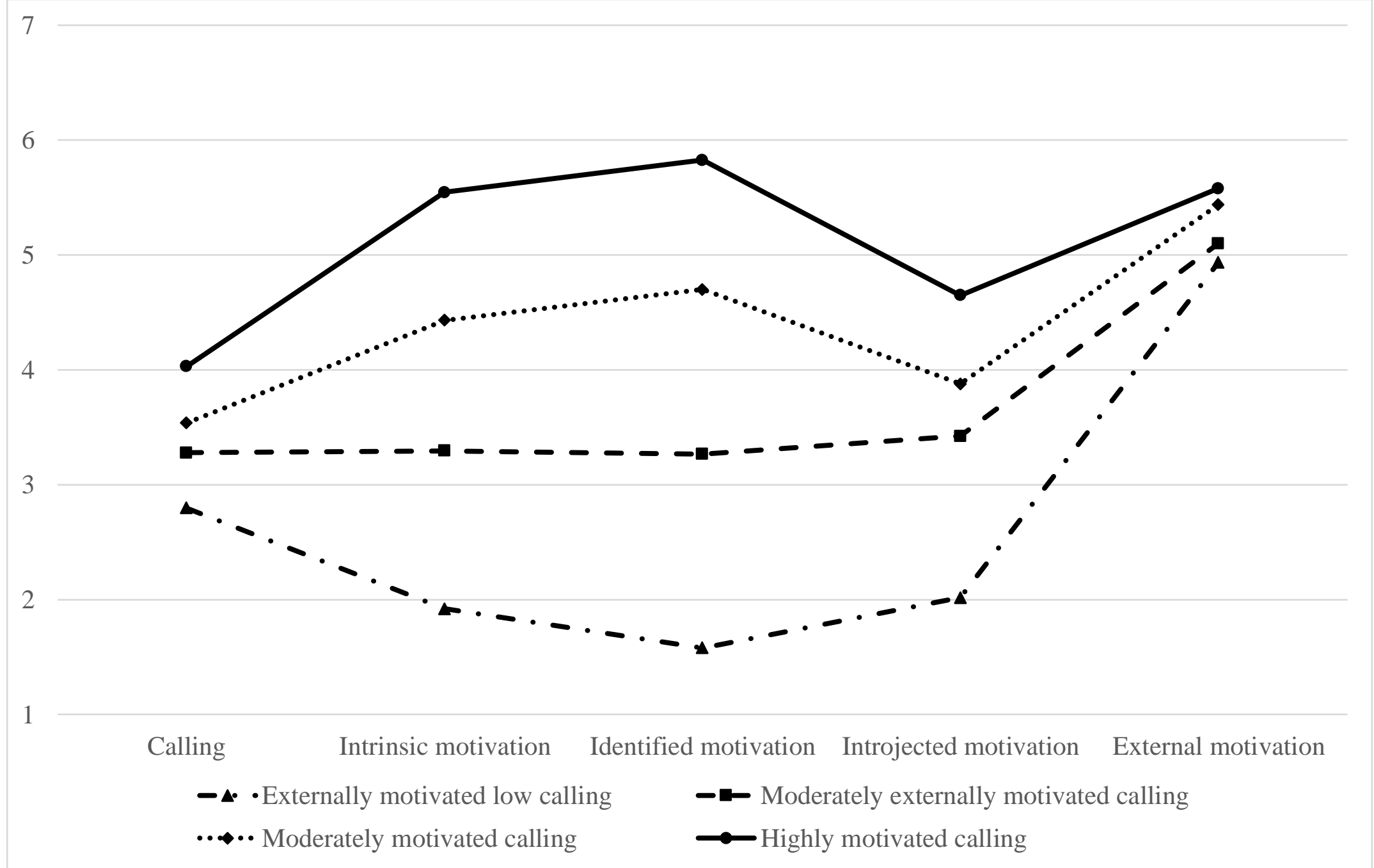

Figure 1. Latent Profiles with Calling and Work Motivations as Profile Indicators. 